\title{
Impact of Corporate Social Responsibility on Corporate Performance: A Study on Commercial Banks of Bangladesh
}

\author{
Trina Saha* Fatema Jannat \\ Department of Business Administration, Noakhali Science and Technology University, PO Box No-3814, \\ Sonapur, Noakhali, Bangladesh
}

\begin{abstract}
This study is focused on the influences of corporate social responsibility on the performance of the commercial banks of Bangladesh. Most of the commercial banks are covered in this study. The independent variable (corporate social responsibility) have been analyzed by several indicators. Primary data has been collected from 200 respondents through a self-administered questionnaire and secondary data has been collected from recently published articles, research papers, annual report, conference proceedings, survey report, internship report, and websites etc. which are relevant to the subject matter of the study. To measure reliability and validity of the study, reliability statistics and KMO and Bartlett's Test have been adopted. In both test the sample size and data are proved to be reliable and valid for the study. To measure the relationship between corporate social responsibility and corporate performance, regression and correlation method have been done. The regression coefficients of most of the indicators of independent variable have significant values to prove the sufficient influence on the dependent variable (corporate performance). The correlation coefficient also proves a strong relationship between dependent and independent variable. The study concludes that as there is huge impact of social responsibility on corporate performance, the corporations should be ethically responsible and go forward for providing more contribution to the society to make sure sustainable growth of the industry and betterment of the people of the country.
\end{abstract}

Keywords: Corporate Social Responsibility, Corporate Performance, CSR practices.

DOI: $10.7176 / \mathrm{EJBM} / 11-5-02$

\section{Introduction}

The purpose of business is to make money. However, the profit motive is sometimes viewed as less than virtuous because it emphasizes self-interest. Nevertheless, self-interest is not the same as selfishness, which emphasizes one's own interests at others' expense. Self-interest is simply a concern for financial reward and is arguably necessary if society is to be maximally productive and efficiently allocate its resources. Consequently business organizations cannot operate successfully without the cooperation of the society in which it is located. The corporate world has some of the brightest minds in the world and it possesses tremendous financial resources. Thus, businesses should utilize some of their human and financial capital in order to "make the world a better place. Corporate responsibility is achieved when a business adapts all of its practices to ensure that it operates in ways that meet, or exceed the ethical, legal, commercial and public expectations that society has of business. Being socially responsible means not only fulfilling legal expectations, but also going beyond compliance and investing "more" into human capital, the environment and the relations with stakeholders. The banking sector has emerged as the most prominent player in practicing Corporate Social Responsibility in Bangladesh. CSR bind banks in a relation with society people showing the caring face of it in different situation, especially, in crisis period.

\section{Literature Review}

Management without caring needs and expectation of stakeholders in a community will not be competitive compared with those who do in the 21 st century. Demand for accountability and transparency from the both public and private sectors has become soaring. In the older days' management is seeking for survival and profits.

It expressed in concern for the health and well-being of employees, their training and participation in the business, equality of opportunities and work family relationship (Vives, 2006) while external CSR refers to responsibility for local community as well as business partners, suppliers, customers, public authorities and NGOs' representing local communities and the environment such as philanthropy, volunteerism and environmental protection (European Commission,2001).

The importance of CSR has become an important issue for banks to address ahead of corporate scandals in the beginning of the century, which have had resulted in a side in the level of trust that they used to enjoy. Wise and Ali (2009) pointed out that CSR is still an evolving concept that enables corporate executives to create and apply self-determined policies to best meet the needs and demands of its stakeholders. Dusuki and Dar (2005) identifies several driving forces behind the growing trend towards CSR initiatives like growing market pressure on social and ethical issues, regularity pressure, increased power of communication etc. This is true that banks are paying more to their CSR activities but not so much as their earning increase. Wartick and Cochran (1985) depicted the evolution of the corporate social performance model by focusing on three challenges to the concept of corporate social responsibility: economic responsibility, public responsibility, and social responsiveness. Hackston and 
Milne (1996) used six categories: environment, energy, human resources, product and safety, community involvement, and other.

It is also recognized as Corporate Responsibility, Corporate Citizenship, Responsible Business, or Social Action Program, Sustainable Responsible Business (SRB), Corporate Social Performance or Corporate Sustainability and Responsibility. It is gratifying more and more vital initiative of businesses both nationally and internationally. Proponents argue that corporations make more long term profits by operating with a perspective.

Corporate social responsibility effect the performance of the organization in different ways. It helps to increase the financial performance of the company so that company will grow rapidly and gain maximum revenue in the market. If a company will follow CSR and try to satisfy their stakeholders then it will definitely able to beat competitors. From last few decades there is a rapid growth in the corporate social responsibilities issues and activities. CSR is one of corporation's responsibilities to its stakeholder and also a voluntary contribution by corporation to sustainable development (Crane and Matten, 2007).

"Furthermore the researches using market based variables and their theory define a consistent relationship between social and financial performance" (Wood \& Jones, 1995). Becchetti et al. (2005) has inspected the performance and profit maximizing conditions in a product differentiation model. The degree of stakeholders and CSR are vigorously influenced by traditional approach. The pragmatic conclusions maintain the hypothesis that motivation of customers is varied to pay for social and environmental concern and vigorously overcome by tendency persistence. This is socially required that a corporation should focus on broader view and also take care of society and environment.

Nowadays management concerns managing financial and nonfinancial results with awareness of risk and maintenance of transparency. As a result, Corporate Social Responsibility (CSR) has possessed equal importance of corporate financial performance (Yeung, 2011). There is an illusion/myth that CSR is just another name for philanthropy. Nevertheless, CSR is not just philanthropy it is more than that. CSR is a concept whereby companies integrated social and environmental concerns into their business operation and interaction with their stakeholders on a voluntary basis. CSR has internal and external practices. Internal refers to directly related with physical and psychological working environment of employees. (Turker, 2009).

Despite the fact that CSR as a perspective is growing, there has always been critics. One of the most influential critics is Nobel Prize winner in economy Milton Friedman, who claims that companies' sole purpose is to maximize profit for their stockholders. Furthermore, he claims that CSR is a waste of the stockholders' money (Friedman, 1962). He had argued that the primary responsibility of business is to make a profit for its owners, albeit while complying with the law. According to this view, the self-interested actions of millions of participants in free markets will, from a utilitarian perspective, lead to positive outcomes for society. If the operation of the free market cannot solve a social problem, it becomes the responsibility of government, not business, to address the issue.

The discussions on CSR practices in Bangladesh in its modern global terms, is relatively new. In general, it is true that in Bangladesh, the status of labor rights practices, environmental management and transparency in corporate governance is not satisfactory, largely due to poor enforcement of existing laws and inadequate pressure from civil society and interest groups like Consumer Forums. Globally, as CSR practices are gradually being integrated into international business practices and hence is becoming one of the determining factors for market accesses, it is becoming equally instrumental for local acceptability.

A focus on CSR in Bangladesh would be useful, not only for improving corporate governance, labor rights, work place safety, fair treatment of workers, community development and environment management, but also for industrialization and ensuring global market access. By now, many CSR dimensions are practiced in Bangladesh (Miyan 2006, Mondol,2009)

Though CSR is a relatively new concept in Bangladeshi corporate culture, awareness of corporate social reporting has rapidly increased. All companies need to consider their CSR for two basic reasons. Firstly, there is intensifying pressure from stakeholders to do so (Belal, 2001 cited Azim 2011). Any company that does not develop and promote its CSR policy to all stakeholders will face increasing threats to its reputation. Secondly, because it makes sound business sense, CSR enhances the reputation of an organization, brings in new business and improves stakeholder return (Azim 2011).

Wise and Ali (2009) in a paper entitled Corporate Governance and Corporate Social Responsibility in Bangladesh with special reference to commercial banks pointed out that corporate Social Responsibility is associated with corporate governance and ethical business procedure. Good corporate governance is expected to under pin effective and efficient corporate social responsibility within firms.

Masud and Hossain (2012) conduct a survey among 10 commercial banks and found that 100 banks reported their CSR activities but $60 \%$ banks participated in prescribe CSR area according to financial act. The literature recognizes that CSR practices differ from country to country and between developed and developing countries (Imam, 2000).

Furthermore Hossain et al. (2006) investigated CSR by using the annual reports of 107 non-finance companies, for the financial year 2002-2003, showing that: an average $8.33 \%$ of Bangladeshi companies disclose social and 
environmental information in their corporate annual report. They concluded that the disclosure of social and environmental information made by the listed companies in their corporate annual reports in Bangladesh is "very disappointing" (Hossain et al., 2006 cited Azim 2011).

Though it is explained that CSR is a set of practices that forms a part of good management or business practices much of it is about transparency and disclosure. Many organizations find that in actuality they already do much of what is considered "CSR" but often do not have formalized systems to report on those activities.

Since Bangladesh is now exposed to global standards, it can be anticipated that the CSR activities in Bangladesh will continue to be extended. Firms are now trying to uphold their corporate image of socially responsible firms and consequently influence consumer buying decisions in favour of the goods and services marketed by them (Miyan M Alimullah September 2006 ).Additionally CSR should not be viewed as an add-on activity as it is a concept of good practice that cuts across an organization (Belal 2008).

\section{Research Problem}

Corporate social responsibility is one of the most prominent issues in the present business environment. Organizations are now looking for sustainable growth rather than only profit maximization. There have been good number of research on CSR but there is paucity of research findings in our country regarding its impact on the performance of the organization. In this study maximum numbers of commercial banks have been selected. So, it is undoubtedly marked that there is a research gap and to mitigate this gap a rigorous research is yet to be systematically attempted.

\section{Rationale of the Study}

Organizations with well-defined social responsibility programs can improve their brand reputation, attract more job candidates and customers and increase employee engagement. The banking sector in our country is the heart of our economy. It has to keep pace with the global change. Corporate Social Responsibility is one of the most common terms in the banking industry as well as in corporate world. As every person has his own social responsibilities towards the society so does the business firms. The idea is that, the business has social obligations and above and beyond making a profit that is corporate social responsibility. CSR significantly improves business house reputation and confidence of customers and business partners, and motivates the employees to work for a company they could feel proud of. These issues motivates the current research to be pursued to find out the real picture of corporate social responsibility practices and how it influences the performance of the corporations playing in the market. Furthermore, the present study may contribute to further research with implications for business growth and stability.

\section{Methodology of the Study}

\subsection{Population and Sample}

The present study is the result of the collection of both primary and secondary data and their analyses of which the primary data have been collected from the sample size of 200 respondents using 'convenience sampling' method through survey. Target population is official of different government owned and private commercial banks of Bangladesh. For collection of primary data survey has been conducted in August 2018.

\subsection{Method of Data Collection}

Data used to find out the impacts of CSR on Corporate Performance have been collected through questionnaire survey. The main instrument of data collection is questionnaire survey. A five point Likert Scale from Strongly Disagree $=1$ to Strongly Agree $=5$, with a set of statements has been used in the questionnaire to collect data. On the other hand secondary data have been collected from several research papers, internship reports, annual reports of several banks, survey reports etc.

\subsection{Development of Hypothesis}

To develop sound relationships with employees organizations are using corporation social responsibility (CSR) as a strategic tool. Corporate social responsibility is being utilized by leading organization to establish good association not only with external stakeholders but also internal stakeholders as well for example employees. This study therefore, investigates the effects of CSR Practices on Corporate Performance in the context of banking sector. The Hypotheses are:

H1: Corporate Performance is influenced by CSR Practices.

H0: Corporate Performance is not influenced by CSR Practices.

\subsection{Variables and Data Analysis Tools of the Study}

This study examines the dynamic influence of CSR Practices on Corporate Performance. Corporate performance is the dependent variable of this study. Therefore the independent variable in this study is corporate social 
responsibility (CSR) Practices. The analyses to find out the impact of CSR on corporate performance has been made by descriptive method using SPSS version 16.0. Primary data is collected through survey questionnaires and hypotheses are tested on the basis of collected data. The dependent variable and independent variable are tested on the basis of some key factors.

\section{Analysis and Findings of the Study}

\subsection{Reliability Statistics}

In the table of reliability statistics we see that Cronbach's Alpha value is .815 and number of items is 20 . The result is greater than 0.7 which indicates that the items have relatively high internal consistency. Both the sample size and data are reliable thus it can be concluded that the study is adequate in every viewpoint.

Table 1: Reliability Statistics

\begin{tabular}{|l|l|}
\hline \multicolumn{2}{|l|}{ Reliability Statistics } \\
\hline Cronbach's Alpha & N of Items \\
\hline .815 & 20 \\
\hline
\end{tabular}

Source: Field Survey

\subsection{Validity Analysis}

The following table represents Kaiser-Meyer-Olkin value of .793 which is more than 0.7 indicating that data are suitable for research study. In Bartlett's Test of Sphericity the significance level is less than 0.05 which indicates the result is valid. The approximate Chi-Square is 885.415 with 190 degree of freedom which is greater than the table value. This rejects the null hypothesis that the correlation matrix is identity matrix. So it can be said that samples are not from population with equal variance. Therefore the KMO and Barlett's Test of Sphericity is significant.

Table 2 : KMO and Bartlett's Test

\begin{tabular}{|ll|l|}
\hline Kaiser-Meyer-Olkin Measure of Sampling Adequacy. & .793 \\
Bartlett's Test of Sphericity & Approx. Chi-Square & 885.415 \\
& df & 190 \\
Sig. & .000 \\
\hline
\end{tabular}

\subsection{Regression Analysis}

Regression analysis has been used to understand the influence of independent variable (CSR practice) on the dependent variable (corporate performance).

Table 3a represents the regression analysis results. To determine the goodness of fit of regression model the multiple correlation coefficient $(\mathrm{R})$ represents the absolute value of coefficient correlation. Here the value is .766 which indicates a degree of correlation. $\mathrm{R}$ square of the regression is the fraction of the variation dependent variable is predicted by independent variable. The result of $\mathrm{R}$ square is .59 which means that $59 \%$ of the variation is dependent variable i.e. corporate performance is explained by independent variable i.e. CSR practice.

\begin{tabular}{|l|l|l|l|l|}
\hline \multicolumn{5}{|l|}{ Table 3a: Model Summary } \\
\hline Model & R & R Square & Adjusted R Square & Std. Error of the Estimate \\
\hline 1 & $.766^{\mathrm{a}}$ & .59 & .565 & .26347 \\
\hline
\end{tabular}

a. Predictors: (Constant), CSR contribution, CSR actions, Contribution in Disaster Management, Contribution in educational, Community Development, Contribution in Arts and Cultural sector., Environmental Responsibility, Contribution in health sector, CSR policy , CSR budget

The Adjusted R Square value of .565 indicates the model is well because this value is very close to R Square with a small difference of .03 (.59-.56). This means that if the model is applied to the population only $3 \%$ less variance would be accounted for. Standard error of the regression also known as the standard error of the estimated represents the average distance that the observed values fall from the regression line. Here the value of .263 shows the observations are closer to the fitted line.

The results of ANOVA are presented in the above table $3 \mathrm{~b}$. Of all information presented in the ANOVA table, the major interesting column is "Sig" column. Any value less than .05 will result in significant effects, while any value greater than 0.05 will result in no significant effects. Here the value is .000 which means the model has a significant fit to the overall data. The F ratio is highly significant and this means that the model significantly improves the ability to predict the outcome variable and best fits the population from which the data were sampled. 
Table 3b: ANOVA ${ }^{b}$

\begin{tabular}{|l|l|l|l|l|l|}
\hline Model & Sum of Squares & df & Mean Square & F & Sig. \\
\hline 1 Regression & 18.649 & 10 & 1.865 & 26.865 & $.000^{\mathrm{a}}$ \\
Residual & 13.119 & 189 & .069 & & \\
Total & 31.768 & 199 & & & \\
\hline
\end{tabular}

a. Predictors: (Constant), CSR contribution, CSR actions, Contribution in Disaster Management, Contribution in educational, Community Development, Contribution in Arts and Cultural sector., Environmental Responsibility, Contribution in health sector, CSR policy, CSR budget

b. Dependent Variable: Corporate Performance

Table 3c: Coefficients ${ }^{\mathrm{a}}$

\begin{tabular}{|c|c|c|c|c|c|}
\hline \multirow[b]{2}{*}{ Model } & \multicolumn{2}{|c|}{$\begin{array}{l}\text { Unstandardized } \\
\text { Coefficients }\end{array}$} & \multirow{2}{*}{$\begin{array}{l}\text { Standardized } \\
\text { Coefficients }\end{array}$} & \multirow[b]{2}{*}{$\mathrm{t}$} & \multirow[b]{2}{*}{ Sig. } \\
\hline & B & Std. Error & & & \\
\hline 1 (Constant) & .683 & .238 & & 2.874 & .005 \\
\hline CSR policy & .073 & .031 & .127 & 2.354 & .020 \\
\hline Community Development & .132 & .031 & .234 & 4.256 & .000 \\
\hline Contribution in health sector & .142 & .026 & .282 & 5.365 & .000 \\
\hline Contribution in educational & .037 & .032 & .059 & 1.167 & .245 \\
\hline Contribution in Arts and Cultural sector. & .071 & .026 & .140 & 2.754 & .006 \\
\hline Contribution in Disaster Management & .036 & .026 & .069 & 1.378 & .170 \\
\hline Environmental Responsibility & .122 & .032 & .202 & 3.852 & .000 \\
\hline CSR budget & .104 & .032 & .187 & 3.213 & .002 \\
\hline CSR actions & .052 & .033 & .088 & 1.593 & .113 \\
\hline CSR contribution & .106 & .028 & .180 & 3.763 & .000 \\
\hline
\end{tabular}

a. Dependent Variable: Corporate Performance

The coefficient table shows the $b$ value, beta and $t$ value. This table shows the effect of independent variable on the dependent variable. For example, every unit increase in CSR contribution would change corporate performance by $10.6 \%$. The beta coefficients is used to explain the relative importance of dependent variables in contributing independent variable. The variables with smaller significant value and greater $\mathrm{t}$ value have the greater contribution to the dependent variable.

\subsection{Correlation Analysis}

Table 4a: Descriptive Statistics

\begin{tabular}{|l|l|l|l|}
\hline & Mean & Std. Deviation & N \\
\hline Corporate Performance & 4.1855 & .39955 & 200 \\
CSR Practices & 4.0530 & .33564 & 200 \\
\hline
\end{tabular}

\section{Table 4b: Correlations}

\begin{tabular}{|ll|l|l|}
\hline & & Corporate Performance & CSR Practices \\
\hline Corporate Performance & Pearson Correlation & 1 & $.745^{* *}$ \\
& Sig. (2-tailed) & & .000 \\
& $\mathrm{~N}$ & 200 & 200 \\
\hline CSR Practices & Pearson Correlation & $.745^{* *}$ & 1 \\
& Sig. (2-tailed) & .000 & 200 \\
& $\mathrm{~N}$ & 200 & \\
\hline
\end{tabular}

\footnotetext{
**. Correlation is significant at the 0.01 level (2-tailed).
} 
Table $4 \mathrm{~b}$ represents the correlation between Corporate Performance and CSR Practice. We know that Correlation Value ranges from +1 to -1 . When it is zero, it means there is no correlation between the variables. Here the correlation value is .745 . This means changes in dependent variable are strongly correlated with the changes in independent variable by $74 \%$. So, it can be said that there is strong correlation between the CSR practices and Corporate Performance. In the table 4a, we see that its CSR practice is in quite good position with a mean value of 4.05. That means, commercial banks CSR Practice has significant impact on their Corporate Performance.

\section{Conclusion}

It can be concluded from the study that CSR has significant impact on the performance of the organizations and the null hypothesis is rejected. As Corporate Social Responsibility has become a criterion of socially lawful business endeavor and the acceptance of it is growing day by day all organizations should have appropriate policy in place for establishing positive organizational culture and social responsible mindset of stakeholders. More focus should be given on community development, health sector and environmental responsibility as these factors have the greater impact on stakeholders mind as well as on corporate performance. Some limitations of this research should be investigated in the future research. This study tried to cover respondents from maximum commercial banks of the study, but further study can be done including all banks and also in other industry of this country.

\section{References}

Azim M., Ahmed E. and Netto D. B. Corporate Social Disclosure in Bangladesh: A study of the Financial Sector. International Review of Business Research Papers, Vol.7 No. 2 March 2011 Pp.37-55.

Becchetti, L., Ciciretti, R. \&Hasan, I. (2007). Corporate Social Responsibility and Shareholder's Valuen Event Study nalysis In possession of Federal Reserve Bank of Atlanta.Working Paper 2007-6, retrieved 29 September 2009, http://ssrn.com/ abstract $=928557$

Belal, A.T. (2001). A study of corporate social disclosures in Bangladesh. Management Auditing Journal 16 (5), 274-289.

Crane, A \& Matten, D (2007). Business Ethics second edition, Oxford University Press, Oxford, UK.

Dusuki A. W. and Dar H.(2005). Stakeholders' Perception of Corporate Social Responsibility of Islamic Bank: Evidence from Malaysia Economy. Proceeding the sixth international conference on Islamic Economics, Jakarta Indonesia on 21-24n November 2005

Edward Probir Mondol (20 Jul 2009). Why Corporate Social Responsibility? -The Context of Bangladesh Published by: Corporate Social Responsibility Bangladesh Foundation

European Commission, "Promoting a European Framework for corporate Social Responsibility Green Paper European Commission Directorate- General for Employment and Social Affairs" Luxembourg. 2001 http://ec.europaeu/education/lifelong-learning-policy/doc/mobility/com329-en.pdf(visited 15 May, 2013)

Friedman, M. (1970). The social responsibility of business is to increase its profits. New York. Times Magazine, December 17: 32-33, 122-126.http://www.alba.edu.gr/uploads/speech.pdf

Hackston D and Milne M (1996). Some determinants of social and environmental disclosures in New Zealand companies. Accounting, Auditing \& Accountability Journal, Vol. 9, No.1, pp.77-108.

Hossain, MA, Islam, KS and Andrew, J, (October 2006). Corporate Social and Environmental Disclosure in Developing Countries: evidence from Bangladesh (Asian Pacific Conference on International Accounting Issues, Hawaii.

Imam S (2000). Corporate Social Performance reporting in Bangladesh. Managerial Auditing Journal vol. 15, 2000 Pp. 133-141

Masud M. A. K. and Hossain M. S.(2012).Corporate Social Responsibility Reporting Practices in Bangladesh: A study of selected Private Commercial Banks. IOSR Journal of Business and Management (ISOR JBM) Vol.06 No. 2 Nov- Dec 2012 42-47

Miyan M Alimullah (2006). Dynamics of Corporate Social Responsibility - Bangladesh Context. Journal of AIUB Bangladesh, August, Vol.3, No. 1, Pp.13-32.

Turker D (2009).Measuring Corporate Social Responsibility: A Scale Development Study. Journal of Business Ethics, 2009, Pp. 411-427.

Uddin, Mohammed Belal et al (January 2008 ). Three Dimensional Aspects of Corporate Social Responsibility. Daffodil International University Journal of Business and Economics, Vol. 3, No. 1.20.

Vives A. (2006).Social and Environmental Responsibility in Small and Medium Enterprises in Latin America. The Journal of Corporate Citizen,2006, Pp. 39-50

Wise Victoria and Ali, M.M (2009). Corporate Governance and Corporate Social Responsibility in Bangladesh with special reference to Commercial Banks. AIUB Bus Econ Working Paper Series, No 2009-05,

Yeung S(2011). The Role of Banks in Corporate Social Responsibility. Journal of Applied Economics and Business Research,( JAEBR) Vol.1 No. 2, 2011, Pp. 13-115 
Wartick, S and Cochran, P (1985). "The Evolution of the Corporate Social Performance Model", Academy of Governance Review, Vol. 10, No. 4.

Wise V. and Ali M. M.(2009).Corporate Governance and Corporate Social Responsibility in Bangladesh with Special Reference to Commercial Banks. AIUB BUS Econ Working Paper Series No 2009.05, 2009.

Wood DJ, Jones RE (1995). Stakeholders mismatching: a theoretical problem in empirical research on corporate social performance. Int. J., Org. Anal., 3(3):229-267. 